\title{
TNF-a G-308A POLYMORPHISM IN POST-MENOPAUSAL WOMEN WITH OSTEOPOROSIS
}

\author{
Talitha Tiffany Alwadris', Listyowati Listyowati' , Antonius Winoto Suhartono' ${ }^{1}$, Lindawati Soetanto Kusdhany², \\ Elza Ibrahim Auerkari ${ }^{1}$
}

'Department of Oral Biology, Faculty of Dentistry, Universitas Indonesia, Jakarta, Indonesia

${ }^{2}$ Department of Prosthodontics, Faculty of Dentistry, Universitas Indonesia, Jakarta, Indonesia

\begin{abstract}
INTRODUCTION: One of the most common health problems affecting the elderly population in the world is osteoporosis. Osteoporosis is defined as a bone disease characterized by a decrease in bone mass (density), due to inability of the body to control mineral content in bones and accompanied by damage to bone architecture. Osteoporosis is characterized by low bone mass and micro architecturally deteriorated bone tissue, along with increased both bone fragility and susceptibility to fracture. Genetic polymorphism of the tumor necrosis factor alpha (TNF- $\alpha$ ) gene is a risk factor for osteoporosis in post-menopausal women. TNF- $\alpha$ acts as a regulator of bone resorption.

ОвјестIVEs: This research aimed to screen for the TNF- $\alpha$ G-308A genetic polymorphism and differentiate its distribution in post-menopausal women with osteoporosis.

MATERIAL AND METHODS: One hundred stored biological samples (50 samples from post-menopausal women with osteoporosis and 50 healthy control samples) were analyzed, using polymerase chain reaction-restriction fragment length polymorphism (PCR-RFLP) technique with the Ncol restriction enzyme. Subsequently, they were assessed statistically using $\chi^{2}$ test.

RESULTS: The AG genotype was the most frequent genotype in both samples. Fisher's exact test revealed no significant association between the TNF- $\alpha$ G-308A polymorphism and post-menopausal osteoporosis $(p=0.117)$.

ConcLusions: The TNF- $\alpha$ G-308A genetic polymorphism was detected in post-menopausal Indonesian women. However, it was not associated with osteoporosis in these populations.
\end{abstract}

KEY wORDs: TNF- $\alpha$ G-308A, polymorphism, PCR-RFLP, post-menopausal, osteoporosis.

J Stoma 2020; 73, 5: 225-230

DOI: https://doi.org/10.5114/jos.2020.100504

\section{INTRODUCTION}

According to the World Health Organization, elderly people are individuals aged 65 years and above, and include the elderly group (60-74 years), the old-age group (75-90 years), and the very-advanced-age group (above 90 years) [1]. Indonesia is a country with an aged population, as the elderly population represented $>7 \%$ of the total population in 2008, 2009, and 2012. Regarding the sexes, women are overrepresented in the most elderly population of Indonesia.

Osteoporosis is one of the most common health problems among the elderly population worldwide. Osteoporosis is defined as a bone disease that is characterized by a decrease in mass (density) of the bone as a whole, because of the inability of the body to regulate
JOURNAL OF STOMATOLOGY CZASOPISMO STOMATOLOGICZNE
AdDress for Correspondence: Prof. Dr. Elza I. Auerkari, MS., SpOF(K), Department of Oral Biology, Faculty of Dentistry, Universitas Indonesia, Jl. Salemba Raya No. 4, Jakarta 10430, Indonesia, phone/fax: +62 81284392420, e-mail: elza.ibrahim@ui.ac.id

ReCEIVED: 10.04.2020 • ACCEPTED: 24.06.2020 • PuBlished: 30.10.2020 
mineral content in bones accompanied by damage to the bone architecture, which results in decreased bone strength, bone loss, and an increased risk of fractures. The term osteoporosis refers to bones that are normally mineralized but lack minerals in quantity. Osteoporosis is characterized by a bone mineral content (BMC)/bone mineral density value $>2.5$ standard deviations below the normal average.

The latest research from the International Osteoporosis Foundation revealed that one in four Indonesian women aged 50-80 years are at risk of developing osteoporosis. This risk is also 4 times higher in women vs. men, especially in post-menopausal women. Osteoporosis occurs mostly in post-menopausal women and does not show real physical symptoms, until bone loss occurs at a later age. This is due to a decrease in estrogen levels in the blood of post-menopausal women, because it is no longer produced in the ovaries. Most symptoms of osteoporosis appear after the age of 50; therefore, early detection of this condition is not easy $[1,2]$.

Osteoporosis is the result of an imbalance in the process of bone remodeling, i.e., an imbalance in the process of bone resorption and bone matrix deposition. Some genetic and environmental factors affect osteoporosis and its associated phenotypes. Genetic factors play an important role in the pathogenesis of osteoporosis, rather than a combination of dietary, hormonal, environmental, and lifestyle factors [3]. The genetic factors that affect bone remodeling include the receptor activator of NF- $\kappa B$ ligand (RANKL), the receptor activator of NF- $\mathrm{KB}$ (RANK), osteoprotegerin (OPG), and cytokines, such as interleukin 1 (IL-1), IL-6, and the tumor necrosis factor $\alpha$ (TNF- $\alpha$ ) [4].

The TNF- $a$ gene, which is one of the genes that influence the process of bone resorption, is a potent cytokine with a wide range of proinflammatory activities that was discovered by Carswell et al. in 1975, and is considered one of the major cytokines associated with inflammatory processes and immune responses. The main physiological effect of TNF- $\alpha$ is the initiation of an immunological and inflammatory response by deploying neutrophils and monocytes at the site of inflammation, followed by activation. Therefore, the TNF- $\alpha$ gene has various effects on the body. The forming genes are in the class III region of the major histocompatibility complex (MHC), 250 centromeric kilobases from the HLA-B locus, and 850 centromeric kilobases from HLA-DR [4, 5] (Figure 1).

TNF- $\alpha$ is an inflammatory cytokine that manages bone metabolism and has been shown to trigger bone resorption in in vitro studies. The stimulatory effect of TNF- $\alpha$ on osteoclast formation has been demonstrated in bone marrow cultures in humans and mice. The lack of estrogen in post-menopausal women can cause the activation of cytokine production, which in turn increases bone resorption $[6,7]$.

TNF- $\alpha$ is thought to play a role in osteoclastic bone resorption in estrogen-deficiency conditions. TNF increases osteoclastogenesis by inducing the expression of activator receptors for nuclear factor-JB ligand 10, and indirectly activating mature osteoclasts through primary effects on osteoblasts and the inhibition of osteoclast apoptosis. TNF runs its activities through the TNF receptor (TNFR), which consists of TNFRI and TNFRII. In vitro studies have shown that the two receptors regulate the process of osteoclastogenesis distinctly. The soluble TNFRI/sTNFRI and TNFRII (sTNFRII) forms stem from the extracellular binding domains of the two receptors. In addition, TNF- $a$ can be a local mediator of osteoclast activity, but in turn, an increased osteoclast activity is associated with age-related bone loss. Therefore, components of the TNF-TNFR system may candidate gene loci for osteoporosis [7].

The TNF- $\alpha$ G-308A polymorphism is characterized by and alteration of a guanine $(G)$ nucleotide to an adenine $(A)$ at position 308 in the promoter region of the gene. The A allele is a mutant (polymorphic) allele; therefore, the genotypes that contain an A allele (AG and AA) experience polymorphism (polymorphic genotypes). The $\mathrm{G}$ allele is a non-polymorphic allele; thus, the GG genotype is a genotype that does not experience polymorphism (non-polymorphic genotype).

TNF- $\alpha$ plays an important role in osteoclastic bone resorption in estrogen deficiency conditions. TNF increases osteoclastogenesis by promoting the expression of activator receptors for JB-10 ligand-factor and activating osteoclasts through indirect primary effects on osteoblasts and inhibiting osteoclast apoptosis. TNF carries out its activities through TNFR, which

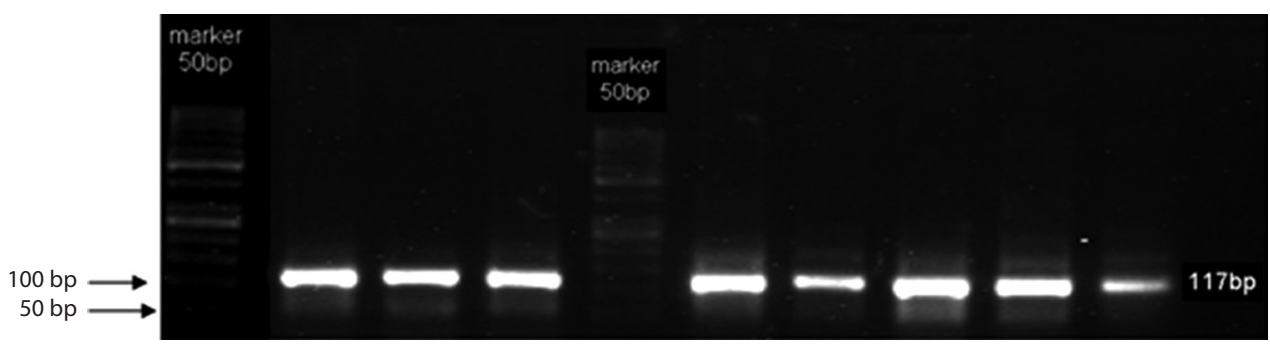

FIGURE 1. Visualization of PCR products after amplification of the samples using TNF-a G-308A forward and reverse primers. PCR amplification resulted in one single band (117 bp) 
consists of TNFRI and TNFRII. In vitro studies show that the two receptors differ in the process of osteoclastogenesis. The soluble forms of TNFRI (soluble TNFRI/sTNFRI) and TNFRII (sTNFRII) can be obtained from extracellular connecting domains of the two receptors. In addition, TNF- $\alpha$ can be a local mediator in osteoclast activity, and osteoclast activity is associated with age-related bone loss. Therefore, components in the TNF-TNFR system can be candidate gene loci for osteoporosis [8].

\section{OBJECTIVES}

This research aimed to screen for the TNF- $\alpha$ G-308A genetic polymorphism and differentiate its distribution in post-menopausal women with osteoporosis. In Indonesia, the TNF- $\alpha$ gene polymorphism has not been investigated in the context of osteoporosis. It is hoped that, through this research on the TNF- $\alpha \mathrm{G}-308 \mathrm{~A}$ polymorphism in post-menopausal women with osteoporosis, polymorphism of this gene can be used as a predictor of osteoporosis in the future.

\section{MATERIAL AND METHODS}

This study was performed with a written approval from the ethics committee of the Faculty of Dentistry, Universitas Indonesia (No. 53/ Ethical Approval/FKGUI/ VII/2017).

This study used materials of DNA extracted from the blood serum of post-menopausal women with osteoporosis and samples of healthy individuals as controls (50 samples each), using a method described by Auerkari et al. [9-11]. The samples were stored as the research material obtained from the Oral Biology Laboratory, Faculty of Dentistry, Universitas Indonesia. Subsequently, the samples were kept deep-frozen at $-20^{\circ} \mathrm{C}$.

The TNF- $\alpha$ G-308A polymorphism was amplified using the following primers: forward, 5'-AGGC AATAGGTTTTGAGGGCCAT-3', and reverse, 5'-ACA CTCCCCATCCTCCCGGCT-3'. PCR was per-formed on a conventional PCR machine in a total volume of $20 \mu \mathrm{l}$ for each sample, containing $10 \mu \mathrm{l}$ of master mix (Taq Bioline), $0.75 \mu \mathrm{l}$ of each primer, $8.4 \mu \mathrm{l}$ of $\mathrm{ddH}_{2} \mathrm{O}$, and $0.1 \mu \mathrm{l}$ of genomic DNA. The PCR conditions consisted of $4 \mathrm{~min}$ of initial denaturation at $94^{\circ} \mathrm{C}$, followed by 35 cycles of denaturation at $95^{\circ} \mathrm{C}$ for $30 \mathrm{~s}$, annealing at $56^{\circ} \mathrm{C}$ for $35 \mathrm{~s}$, and elongation at $72^{\circ} \mathrm{C}$ for $15 \mathrm{~s}$, with final elongation step at $72^{\circ} \mathrm{C}$ for $5 \mathrm{~min}$. The PCR products were electrophoresed at $80 \mathrm{~V}, 400 \mathrm{~mA}$ for $30 \mathrm{~min}$ in $1.5 \%$ agarose gels stained with Gel Red. The length of the fragments was measured using a $50 \mathrm{bp}$ DNA marker (ThermoScientific).

PCR was followed by the application of the restriction fragment length polymorphism (RFLP) genotyping method using the NcoI restriction enzyme (Thermo-
Scientific), which produced one fragment (117 bp) for the $\mathrm{G}$ allele and two fragments (97 and $20 \mathrm{bp}$ ) for the A allele. For RFLP, the tubes were placed in an incubator at $37^{\circ} \mathrm{C}$ for 16 hours; then the enzyme was inactivated at $65^{\circ} \mathrm{C}$ for $20 \mathrm{~min}$ using a thermoblock. The fragments were separated by electrophoresis at $80 \mathrm{~V}, 400 \mathrm{~mA}$ for $40 \mathrm{~min}$ in $3.5 \%$ agarose gels stained with Gel Red for visualization using Gel Doc.

Hardy-Weinberg equilibrium was assessed using the $\chi^{2}$ test. Differences in the distribution of the alleles and genotypes of the TNF- $\alpha$ G-308A gene polymorphism between the two groups were analyzed using Fisher's exact test, because the number of samples did not meet the requirements for the $\chi^{2}$ test. Statistical tests were performed using SPSS, version 16 .

\section{RESULTS}

The amplification of the TNF- $\alpha$ gene G-308A promoter region polymorphism yielded a single band of 117 bp (Figure 1). RFLP yielded one fragment for the $\mathrm{G}$ allele (117 bp) and two fragments for the A allele (97 bp and $20 \mathrm{bp}$ ). The genotype of each sample was identified using Gel Doc. The AA genotype was identified by the presence of the two DNA fragments of $97 \mathrm{bp}$ and $20 \mathrm{bp}$ (the NcoI enzyme recognized its restriction site in both alleles). The GG genotype only produced one 117 bp fragment (the NcoI enzyme did not recognize any restriction sites in these alleles). The AG genotype was identified in cases, where the NcoI enzyme only recognized its restriction site in one of the alleles, which yielded three DNA fragments with a length of $117 \mathrm{bp}, 97 \mathrm{bp}$, and $20 \mathrm{bp}$, respectively (Figure 2).

The TNF- $\alpha$ G-308A genetic polymorphism produced three genotypes, namely GG (wild-type homozygote; non-polymorphic), AG (variant heterozygote; polymorphic), and AA (mutant homozygote; polymorphic). The distribution of the alleles and genotypes in the population were estimated using the Hardy-Weinberg test, and a $\chi^{2}$ value of 36.86 was obtained, which meant that the sample population was consistent with the Hardy-Weinberg equilibrium $(p>0.05)$. The distribution of the frequency of genotypes and alleles is presented in Table 1.

The polymorphic genotypes were more frequent in the osteoporosis group (100\%) compared with the control group (92\%). Similarly, regarding the allele frequency distribution, the polymorphic alleles were more frequent in the osteoporosis group (62\%) versus the control group (51\%).

Differences in the distribution of the genotypes and alleles of the TNF- $\alpha$ G-308A genetic polymorphisms between the two groups were analyzed using Fisher's exact test, because the number of samples did not meet the requirements for the $\chi^{2}$ test. $P$-value $>0.05$ were in both the genotype distribution $(p=0.117)$ and 


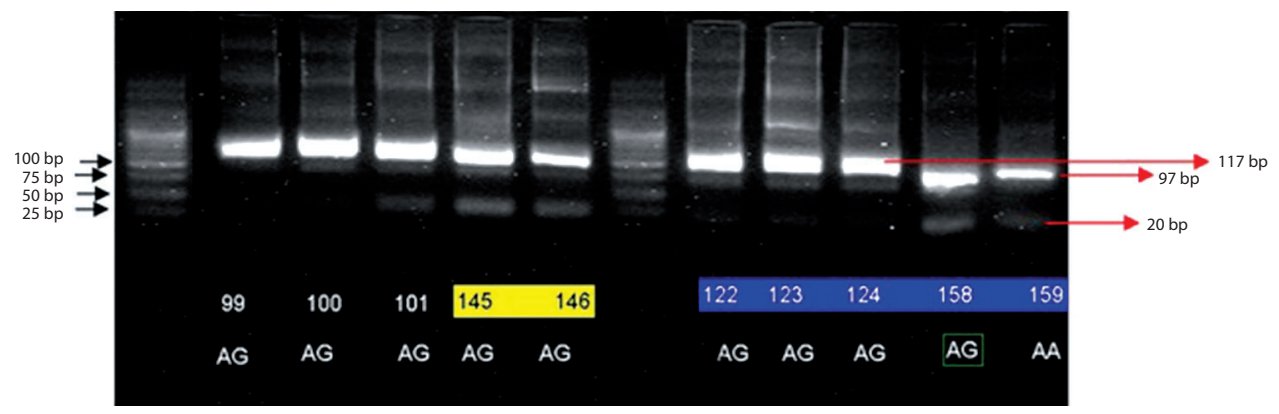

FIGURE 2. Genotyping of the TNF- $\alpha$ G-308A polymorphism. PCR products were restricted using Ncol and separated by electrophoresis. Electrophoresis generated one fragment (117 bp) for the $\mathrm{G}$ allele and two fragments (97 bp and $20 \mathrm{bp}$ ) for the A allele

TABLE 1. Genotype and allele distributions of the TNF-a G-308A gene polymorphism in women with and without osteoporosis

\begin{tabular}{|c|c|c|c|}
\hline \multirow[t]{2}{*}{ Variables } & \multicolumn{2}{|c|}{ Osteoporosis } & \multirow[t]{2}{*}{$p$-value } \\
\hline & Yes , $\boldsymbol{n}(\%)$ & No , $n(\%)$ & \\
\hline \multicolumn{4}{|l|}{ Genotype } \\
\hline AA & $12(24.0)$ & $5(10.0)$ & \multirow[t]{4}{*}{0.117} \\
\hline GG & $0(0.0)$ & $4(8.0)$ & \\
\hline AG & $38(76.0)$ & $41(82.0)$ & \\
\hline Total & $50(100.0)$ & $50(100.0)$ & \\
\hline \multicolumn{4}{|l|}{ Allele } \\
\hline$A$ & $62(62.0)$ & $51(51.0)$ & \multirow[t]{3}{*}{0.15} \\
\hline G & $38(38.0)$ & $49(49.0)$ & \\
\hline Total & $100(100.0)$ & $100(100.0)$ & \\
\hline
\end{tabular}

alleles $(p=0.154)$ of the study sample. The distribution of the alleles $(p=0.117)$ and genotypes $(p=0.154)$ of the TNF- $\alpha$ G-308A genetic polymorphism was not significantly different between post-menopausal women with osteoporosis and healthy individuals.

\section{DISCUSSION}

TNF- $\alpha$ is a proinflammatory cytokine that affects bone metabolism by increasing bone resorption and inhibiting osteoblast differentiation. Many microsatellite markers and SNPs have been identified in this cluster, including the substitution of a guanine base to an adenine at position -308 in the 5 ' region of the gene (rs1800629) [12]. The relationship between the TNF- $\alpha$ gene polymorphism and osteoporosis has been studied in various populations, but not among the Indonesian inhabitants. Therefore, this study aimed to analyze the TNF- $\alpha$ G-308A genetic polymorphism and its relationship with osteoporosis in post-menopausal women in Indonesia.

In the Indonesian population studied here, the polymorphic genotypes were more frequent than were the non-polymorphic ones in both the osteoporosis and the control groups. This was in line with a research conducted among Chinese population [13], in which there were more polymorphic genotypes $(95.9 \%)$ than non-polymorphic $(4.1 \%)$ ones $(79.3 \% \mathrm{AA}, 16.6 \% \mathrm{AG}$, and $4.1 \%$ GG genotypes) in the osteoporosis group. However, that study did not mention the distribution in the control group [13].

Conversely, our results were in contrast with those of the study conducted among a Mediterranean population, in which the non-polymorphic (GG) genotype was more frequent in both the osteoporosis (83\%) and the control (74\%) groups. In the osteoporosis group, $17.1 \%$ of individuals presented with polymorphic genotypes (12.8\% AG and 4.3\% AA genotypes) [2]. There was no AA genotype in the control group, whereas $26 \%$ of the cohort had the AG polymorphic genotype in this Mediterranean population [2].

A similar scenario was reported for a Korean population [14], in which the non-polymorphic (GG) genotype was more frequent in the osteoporosis group (87.4\%) than were the polymorphic genotypes $(12.6 \%$; $11.6 \% \mathrm{AG}$ and $1 \% \mathrm{AA}$ genotypes). In the control group, $92.3 \%$ of individuals had the non-polymorphic (GG) genotype and $7.7 \%$ had a polymorphic genotype (the AG genotype exclusively, as no AA genotype was found in the control group in this Korean population) [14].

Similar findings were described in a study conducted in Poland [14], in which the non-polymorphic (GG) genotype was more frequent in the osteoporosis group (79.41\%) versus polymorphic genotypes (20.59\%; $19.75 \%$ AG and $0.84 \%$ AA genotypes). Among the control group, $67.41 \%$ of individuals had the non-polymorphic (GG) genotype and $32.59 \%$ had polymorphic genotypes (29.46\% AG and 3.13\% AA genotypes) [15]. Distribution of the TNF- $\alpha$ G-308A genotype frequencies are shown in Table 2.

In the Indonesian population, the polymorphic allele A was more frequent in both post-menopausal women (62\%) and healthy individuals (51\%) compared with the non-polymorphic $\mathrm{G}$ allele. These results are not 
TABLE 2. Distribution of the TNF-a G-308A genotype frequency in several post-menopausal female populations

\begin{tabular}{|c|c|c|c|c|}
\hline Research & Population & Genotypes & Osteoporosis group (\%) & Control group (\%) \\
\hline \multirow[t]{3}{*}{ Alwadris et al. (2017) } & \multirow[t]{3}{*}{ Indonesia } & GG & 8.0 & 0 \\
\hline & & AG & 82.0 & 76 \\
\hline & & $A A$ & 10.0 & 24 \\
\hline \multirow[t]{3}{*}{ Chen et al. (2005) } & \multirow[t]{3}{*}{ China } & GG & 4.1 & \\
\hline & & AG & 16.6 & \\
\hline & & $A A$ & 79.3 & \\
\hline \multirow[t]{3}{*}{ Fontova et al. (2002) } & \multirow[t]{3}{*}{ Mediterranean } & GG & 83.0 & 74 \\
\hline & & AG & 12.8 & 26 \\
\hline & & $A A$ & 4.3 & 0 \\
\hline \multirow[t]{3}{*}{ Kim et al. (2009) } & \multirow[t]{3}{*}{ Korea } & GG & 87.4 & 92.3 \\
\hline & & AG & 11.6 & 7.7 \\
\hline & & $A A$ & 1.0 & 0 \\
\hline \multirow[t]{3}{*}{ Kotrych et al. (2016) } & \multirow[t]{3}{*}{ Poland } & GG & 79.41 & 67.41 \\
\hline & & AG & 19.75 & 29.46 \\
\hline & & $A A$ & 0.84 & 3.13 \\
\hline
\end{tabular}

TABLE 3. Distribution of the TNF-a G-308A allele frequency in several post-menopausal female populations

\begin{tabular}{|c|c|c|c|c|}
\hline Research & Population & Allele & Osteoporosis group (\%) & Control group (\%) \\
\hline \multirow[t]{2}{*}{ Alwadris et al. (2017) } & \multirow[t]{2}{*}{ Indonesia } & G & 38.0 & 49.0 \\
\hline & & A & 62.0 & 51.0 \\
\hline \multirow[t]{2}{*}{ Fontova et al. (2002) } & \multirow[t]{2}{*}{ Mediterranean } & G & 87.0 & 89.4 \\
\hline & & A & 10.6 & 13.0 \\
\hline \multirow[t]{2}{*}{ Kotrych et al. (2016) } & \multirow[t]{2}{*}{ Poland } & G & 10.71 & 17.86 \\
\hline & & A & 89.2 & 82.14 \\
\hline
\end{tabular}

consistent with the study conducted among the Mediterranean population [2], in which the non-polymorphic $\mathrm{G}$ allele was more frequent in the osteoporosis group $(89.4 \%)$ and in the control group (87\%). Allele A was present in only $10.6 \%$ of the individuals in the control group and $13 \%$ of the healthy individuals [2]. A similar scenario was found in the study conducted in Poland [14], in which the non-polymorphic G allele was more frequent in the osteoporosis group (89.29\%) and in the control group (89.29\%) and controls (82.14\%). Moreover, $10.71 \%$ of the individuals in the osteoporosis group and $17.86 \%$ of individuals in the control group carried the polymorphic A allele [15]. Distribution of the TNF- $\alpha$ G-308A allele frequencies are shown in Table 3.

The results of the statistical test ( $p=0.117$ ) of the genotype distribution in the study sample led us to conclude that there was no significant difference in the distribution of the TNF- $\alpha$ G-308A genetic polymorphism between post-menopausal women with osteoporosis and healthy individuals. Although the TNF- $\alpha$ G-308A genetic polymorphism was present in post-menopausal women with osteoporosis, there was no significant difference in its distribution pattern between the control and osteoporosis groups. This may be due to various other factors that play a role in the development of osteoporosis, such as environmental effects that cause an increase or a decrease in the likelihood of disease development and lifestyle, racial and ethnic differences, or the low number of samples used in this study. The polymorphism can be used as a biomarker to confirm the diagnosis and its relations to dental abnormalities, which may be found in osteoporotic patients, and for general considerations in treatment planning.

\section{CONCLUSIONS}

Although this study detected the TNF- $\alpha$ G-308A genetic polymorphism in post-menopausal Indonesian women with osteoporosis, there was no significant difference in its pattern of distribution between post-menopausal women with osteoporosis and healthy individuals. 


\section{ACKNOWLEDGEMENT}

The authors would like to greatly appreciate the financial support from Universitas Indonesia to EIA 2019.

\section{CONFLICT OF INTEREST}

The authors declare no potential conflicts of interest with respect to the research, authorship, and/or publication of this article.

\section{References}

1. Indonesian Ministry of Health Data and Information Center. Data and Conditions for Osteoporosis in Indonesia. Center for Data and Information of the Ministry of Health of The Republic of Indonesia; 2015.

2. Fontova R, Gutiérrez C, Vendrell J, et al. Bone mineral mass is associated with interleukin 1 receptor autoantigen and TNF- $\alpha$ gene polymorphisms in post-menopausal Mediterranean women. J Endocrinol Invest 2002; 25: 684-690.

3. Nigel A, Carolyn D, Harris Cath PL. Osteoporosis. $1^{\text {st }}$ ed. London: Remedica; 2006.

4. Oishi Y, Watanabe Y, Shinoda S, et al. The IL6 gene polymorphism $-634 \mathrm{C}>\mathrm{G}$ and IL17F gene polymorphism $7488 \mathrm{~T}>\mathrm{C}$ influence bone mineral density in young and elderly Japanese women. Gene 2012; 504: 75-83.

5. Pujhari SK, Ratho RK, Prabhakar S, Mishra B, Modi M. TNF-a promoter polymorphism: a factor contributing to the different immunological and clinical phenotypes in Japanese encephalitis. BMC Infect Dis 2012; 12: 23.

6. Vitale RF, Ribeiro FD. The role of tumor necrosis factor-alpha (TNF- $\alpha$ ) in bone resorption present in middle ear cholesteatoma. Braz J Otorhinolaryngol 2007; 73: 123-127.

7. Hospital RH, Kingdom U. Effects of a polymorphism in the human tumor necrosis factor a promoter on transcriptional activation. Proc Natl Acad Sci U S A 1997; 94: 3195-3199.

8. Kim H, Chun S, Ku SY, Suh CS, Choi YM, Kim JG. Association between polymorphisms in tumor necrosis factor (TNF) and TNF receptor genes and circulating TNF, soluble TNF receptor levels, and bone mineral density in postmenopausal Korean women. Menopause 2009; 16: 1014-1020.

9. Auerkari EI, Suryandari DA, Umami SS, et al. Gene promoter polymorphism of RUNX2 and risk of osteoporosis in postmenopausal Indonesian women. SAGE Open Med 2014; 2: 2050312114531571.

10. Jessica C, Alwadris TT, Prasetyo SR, Puspitawati R, Auerkari EI. Association of interleukin 8-251 A/T gene polymorphism with periodontitis in Indonesia. J Phys Conf Ser 2018; 1025: 012071.

11. Auerkari EI, Kusdhany LS, Umami SS, Rahardjo TBW, Talbot C. Polymorphism of methylenehydrofolate reductase (A1298c) as a risk factor for osteoporosis in post-menopausal Indonesian women. Asian J Pharm Clin Res 2017; 10: 172-175.

12. Moffett SP, Zmuda JM, Oakley JI, et al. Tumor necrosis factor-alpha polymorphism, bone strength phenotypes, and the risk of fracture in older women. J Clin Endocrinol Metab 2005; 90: 3491-3497.

13. Chen HY, Chen WC, Hsu CM, Tsai FJ, Tsai CH. Tumor necrosis factor $\alpha$, CYP17, urokinase, and interleukin 10 gene polymorphisms in postmenopausal women: correlation to bone mineral density and susceptibility to osteoporosis. Eur J Obstet Gynecol Reprod Biol 2005; 122: 73-78.

14. Kim H, Chun S, KuS Y, et al. Association between polymorphisms in tumor necrosis factor (TNF) and TNF receptor genes and circulating TNF, soluble TNF receptor levels, and bone mineral density in postmenopausal Korean women. Menopause 2009; 16: 1014-1020.
15. Kotrych D, Dziedziejko V, Safranow K, et al. TNF- $\alpha$ and IL10 gene polymorphisms in women with postmenopausal osteoporosis. Eur J Obstet Gynecol Reprod Biol 2016; 199: 92-95. 